\title{
Dilute-Acid Hydrolysis of Apple, Orange, Apricot and Peach Pomaces as Potential Candidates for Bioethanol Production
}

\author{
Can Ucuncu, Canan Tari*, Hande Demir, Ali Oguz Buyukkileci, and Banu Ozen \\ Department of Food Engineering, Izmir Institute of Technology, Izmir, Gulbahce Campus, \\ TR-35430, Urla-Izmir, Turkey
}

\begin{abstract}
Chemical composition of four selected fruit pomaces (agro-industrial wastes) was evaluated. The effect of temperature, time, acid concentration and solid:liquid $(S: L)$ ratio on dilute-acid hydrolysis of selected pomaces were investigated using $2^{4}$ factorial and central composite design and optimum hydrolysis conditions were determined. A preliminary study was initiated using apple hydrolysate and the fungus Tricoderma harzianum in order to explore and demonstrate their potential uses in bioethanol production. Chemical composition of pomaces was promising as fermentation media. The highest reducing sugar yield from the optimization step was $31 \%, 49 \%, 56 \%$ and $52 \%$ for apple, apricot, orange and peach pomaces, respectively under optimum hydrolysis conditions. Neither furfural nor hydroxmethylfurfural (HMF) were detected in hydrolysates. The highest bioethanol production $(1.67 \mathrm{~g} / \mathrm{L})$ was obtained in 6 days in a non-static incubator using Tricoderma harzianum pregrown in minimal medium. It was demonstrated that selected pomaces holds potential for bioethanol production and can be eliminated without being potential waste problem to the environment, with economical return. Although, this work is an initial study in showing the potential of these pomaces and $T$. harzianum in bioethanol production, an extensive study on the optimization of fermentation parameters is recommended for further increase of bioethanol production.
\end{abstract}

Keywords: Agro-Industrial Waste, Fruit Pomaces, Bioethanol Production, Dilute Acid Hydrolysis, Tricoderma harzianum.

\section{INTRODUCTION}

The search for alternative and sustainable energy sources has become very important since fossil fuels are used continuously to meet the majority of the world's energy demand, causing an increase in the concentrations of $\mathrm{CO}_{2}$ in the atmosphere and raising concern for global warming. ${ }^{1}$ Nowadays, bioethanol is accepted as an answer for this search, since it has the potential to provide significant and unique, economical, environmental and strategic advantages, including disposal of problematic solid wastes, less air pollution, reductions in greenhouse gas emissions, improving energy security and reduction in trade benefits. ${ }^{2,3}$ Indeed, global bioethanol production showed 95\% growth between the years 2000 and 2005 and doubled between 2005 and $2010 .^{4-6}$ In 2011 worldwide ethanol fuel production reached 84.6 billion liters with United States as the top producer followed by Brazil. In fact many countries

*Author to whom correspondence should be addressed

Email: ctari7@yahoo.com have made it mandatory to blend at least $10 \%$ ethanol to current gasoline fuel. ${ }^{7}$ Based on this, the search for alternative and more economical renewable resources in order to meet this demand are among the hot topics attracting many researchers today.

Bioethanol production has mainly three kinds of sources (sugary, starchy and cellulosic (lignocellulosic) materials), which rely on two kind of feedstocks; first and second generation feedstocks. Since first-generation feedstocks are also nutritional sources for living organisms and need redundant agricultural land, there are many problems regarding ethical concerns and favorable economics, leading severe limitations to starch and sugar-based ethanol production. ${ }^{8}$ Second-generation feedstocks, on the other hand, do not raise such concerns since they are mainly wastes and are locally available and abundant. Most of the countries showed serious concern for developing renewable energy sources in an effort to ease the severity of unexpected energy shortages. ${ }^{9}$ Alternatively, fruit industry could be considered as a suitable resource for the secondgeneration feedstocks, since it produces a great amount 
of cellulosic waste, which could be candidate as potential fermentation media. In fact fruit juice processing industry is one of the biggest industries in the World. In 2007, Europe produced 11.7 billion liters fruit juice products followed by North America with 9.5 billion liters production in 2009. ${ }^{10}$ Overall, since $30-50 \%$ of a fruit is pomace, wastes of this sector, which are approximately over $3-4.2 \times 10^{6}$ and $15.6 \times 10^{6} \mathrm{M}$ tons per year globally for apple and citrus fruits, respectively, they raise serious environmental concern. ${ }^{11}$ Feedstock collection, storage, transportation and pretreatment processes are among the major costs of bio-refineries. ${ }^{12}$ On the other hand, fruit pomaces are easy to obtain and are not hardwood or softwood material (harsh and expensive pretreatment methods are not necessary, leading to reduction in bioethanol costs) have considerably high fermentable sugar content, which could prove to be beneficial. As an example, it has been reported that ethanol from citrus peel has more potential economical viability than that of cellulosic ethanol in the bio-fuel industry. ${ }^{13}$ This was based on a cost estimation of ethanol production from citrus waste, performed by NREL and USDA/ARS ${ }^{14-17}$ as $\$ 1.23 /$ gal as compared to lignocellulosic ethanol process $(\$ 1.35-1.62 / \mathrm{gal}) .{ }^{18}$ Another reason, why for example citrus waste-ethanol process was more economical, was because of the generation of citrusderived co-product such as limonene, which could be sold to reduce the ethanol production cost. Similar advantages can also be observed in the case of other pectin rich fruit pomaces. These characteristics of pomaces can make them candidates for all kind of fermentation media.

Pomaces consist of plant cells, whose close physical and chemical associations between lignin and plant cell wall polysaccharides, together with cellulose crystallinity poses limitations for efficient ethanol production from agro-industrial residues. ${ }^{19}$ The protective shield of lignin around cellulose and hemicellulose protects polysaccharides from enzymatic degradation. ${ }^{9}$ Thus, a pretreatment before fermentation must be applied for the solubilisation and separation of the four components; lignin, cellulose, hemicellulose and extractives, in order to decrease cellulose crystallinity and increase the surface area for enzymatic activity. As a general rule pretreatments

(i) must avoid the formation of inhibitors,

(ii) should use inexpensive chemicals and

(iii) should be treated with simple equipment and procedures. $^{20}$

In the present study, fruit pomaces (agro-industrial waste) as potential fermentation media was considered for bioethanol production by first determining its chemical composition and then optimizing the pretreatment conditions using dilute acid hydrolysis in order to obtain high reducing sugar yield (RSY) with minimum inhibitors. The optimization was performed by applying a two-staged experimental design. The first stage consisted of twolevel factorial design with four factors; temperature, acid concentration, solid-liquid ratio and time. Based on the results of the first stage, time and temperature were fixed in the second stage, which was a central composite design with two factors (acid concentration and solid-liquid ratio) employed in order to obtain the optimum levels. Finally, a preliminary fermentation experiment was carried out using optimized apple hydrolysate and the fungus Trichoderma harzianum in order to demonstrate their potential usage in the bioethanol production.

\section{MATERIALS AND METHODS}

\subsection{Fruit Pomaces}

Peach, apricot, apple and orange pomaces were obtained from "Konfrut Fruit Juice Concentrates and Purees, Denizli-Turkey" in ice bags and stored until usage at $-18{ }^{\circ} \mathrm{C}$.

\subsection{Microbial Source}

The fungal strain Trichoderma harzianum (strain NRRL 31396) obtained from (USDA-ARS-US Dairy Forage Research Center, Madison) was chosen for bioethanol production using apple pomace under optimum pretreatment conditions.

\subsection{Chemical Compositional Analysis of Fruit Pomaces}

Protein: Gerhardt Kjeldatherm Digestion System KBL20S with TZ Controller and Vapodest 30S Rapid Steam Distillation Unit (Bonn, Germany) was used to determine the $\%$ protein content of samples using AOAC official method 920.152. ${ }^{21}$ Measurements were repeated three times.

Water activity $\left(a_{w}\right)$ : Water activity of the samples was determined in duplicates using a Rotronic HygroLab Benchtop Humidity Temperature Indicator (Bassersdrof, Germany).

Solids (soluble and insoluble): AOAC official method $922.10 \mathrm{~A}^{21}$ was used to determine water-insoluble solids and soluble solids. Data reported were averages of three measurements.

Ash: The ash content was determined in duplicates using AOAC 940.26 "Ash of fruits and fruit products" procedure.

Dietary fiber (soluble and insoluble): Sigma Total Dietary Fiber Assay Kit was used for determination of soluble and insoluble dietary fiber content. The experiments were duplicated for each pomace.

Initial sugar: In order to determine the total initial reducing sugar content, $100 \mathrm{ml}$ suspension containing $10 \mathrm{~g}$ of each pomace was autoclaved for $5 \mathrm{~min}$ at $105^{\circ} \mathrm{C}$. Afterwards, the filtered liquid part was used for Nelson-Somogyi reducing sugar assay. ${ }^{22}$ Data reported were averages of three measurements. 
Table I. Factors and levels of screening and optimization steps.

\begin{tabular}{|c|c|c|c|c|c|c|c|c|c|c|}
\hline \multicolumn{11}{|c|}{ Screening } \\
\hline Level & \multicolumn{3}{|c|}{ Solid:liquid ratio $(\mathrm{g}: \mathrm{ml})\left[X_{1}\right]$} & \multicolumn{3}{|c|}{ Acid concentration $(\%)\left[X_{2}\right]$} & \multicolumn{2}{|c|}{ Temperature $\left({ }^{\circ} \mathrm{C}\right)\left[X_{3}\right]$} & \multicolumn{2}{|r|}{ Time $(\min )\left[X_{4}\right]$} \\
\hline-1 & \multicolumn{3}{|c|}{$1: 9$} & \multicolumn{3}{|c|}{3} & \multicolumn{2}{|c|}{110} & \multicolumn{2}{|r|}{20} \\
\hline+1 & \multicolumn{3}{|c|}{$1: 7$} & \multicolumn{3}{|c|}{1} & \multicolumn{2}{|c|}{$126^{*}$} & \multicolumn{2}{|r|}{$40^{*}$} \\
\hline \multicolumn{11}{|c|}{ Optimization } \\
\hline & \multicolumn{5}{|c|}{ Solid/Liquid ratio $(\mathrm{g} / \mathrm{ml})\left[X_{1}\right]$} & \multicolumn{5}{|c|}{ Acid concentration $(\%)\left[X_{2}\right]$} \\
\hline Level & -2 & -1 & 0 & +1 & +2 & -2 & -1 & 0 & +1 & +2 \\
\hline Apple & $1 / 11.32$ & $1 / 10.5$ & $1 / 8.5$ & $1 / 6.5$ & $1 / 5.67$ & 0.37 & 1 & 2.5 & 4 & 4.62 \\
\hline Apricot & $1 / 11.32$ & $1 / 10.5$ & $1 / 8.5$ & $1 / 6.5$ & $1 / 5.67$ & 0.37 & 1 & 2.5 & 4 & 4.62 \\
\hline Orange & $1 / 7.62$ & $1 / 7$ & $1 / 5.5$ & $1 / 4$ & $1 / 3.38$ & 0 & 0.41 & 1.41 & 2.41 & 2.81 \\
\hline Peach & $1 / 7.62$ & $1 / 7$ & $1 / 5.5$ & $1 / 4$ & $1 / 3.38$ & 0 & 0.41 & 1.41 & 2.41 & 2.81 \\
\hline
\end{tabular}

Note: * Maximum operational values of autoclave.

\subsection{Dilute-Acid Pretreatment with Phosphoric Acid}

Phosphoric acid was chosen for dilute-acid pretreatment, since after neutralization of hydrolysates with $\mathrm{NaOH}$, the salt formed (sodium phosphate), does not need to be removed from the hydrolysates and can be used as nutrient by microorganisms. All hydrolysis experiments were carried out in an autoclave (Hirayama, HA-300 MIV, Saitama-Japan) using $15 \mathrm{~g}$ of each pomace with the appropriate phosphoric acid concentration under the conditions specified in the experimental design (Table I). Highest attainable temperature and time of the autoclave used in the study was limited to maximum $126{ }^{\circ} \mathrm{C}$ and $40 \mathrm{~min}$, respectively. The time required to reach the desired temperature was not taken into account nevertheless; it was unnoticeably short between 110 and $126{ }^{\circ} \mathrm{C}$. The holding time at the specified temperature was taken as the major parameter in the evaluation of the time effect on the hydrolysis. The time required to reach $110{ }^{\circ} \mathrm{C}$ was the same for all samples. The liquid fraction of hydrolysates was stored at $-18{ }^{\circ} \mathrm{C}$ until use.

\subsection{Analysis of Hydrolysates}

Reducing sugar yield (RSY): In the screening part, HPLC was used for the determination of sugars using a refractive index (RI) detector and a Biorad Aminex HPX-87P column equipped with an appropriate guard column. HPLC conditions applied were such as $20 \mu \mathrm{L}$ of injection volume, $0.6 \mathrm{ml} / \mathrm{min}$ of flow rate, $85{ }^{\circ} \mathrm{C}$ and $50{ }^{\circ} \mathrm{C}$ of column and detector temperature, respectively. The mobile phase was HPLC grade water. Hydrolysates were neutralized to $\mathrm{pH} 7$ using calcium carbonate. Concentrations of each sugar were calculated by comparing the respective peak areas with the ones of the sugar standards using a standard curve. The total reducing sugar yield of the hydrolysate expressed as percentage, was calculated as the ratio of the sum of cellobiose, glucose, xylose, galactose, arabinose, mannose and fructose to the initial dry weight of the pomace. In the optimization part Nelson-Somogyi ${ }^{22}$ reducing sugar assay was used in order to determine the RSY. No interference by phosphoric acid was observed in the experiments conducted (data not shown).

Furfural, hydroxymethylfurfural (HMF) and bioethanol: Furfural, hydroxymethylfurfural and bioethanol content of hydrolysates were determined using HPX-87H column with a flow rate of $0.6 \mathrm{~mL} / \mathrm{min}$. The temperatures of the column and RI detector were $65{ }^{\circ} \mathrm{C}$ and $50{ }^{\circ} \mathrm{C}$, respectively.

FTIR-Spectroscopy Analysis: Hydrolysate samples of screening experiments were scanned using an FT-IR spectrometer (Perkin Elmer Spectrum 100 FT-IR spectrometer, Wellesley, MA) equipped with a deuterated tri-glycine sulphate (DTGS) detector. Samples were placed on a horizontal attenuated total reflectance (HATR) accessory with zinc selenide ( $\mathrm{ZnSe}$ ) crystal (45 deg. Trough Plate). The scanning was carried out at $4.00 \mathrm{~cm}^{-1}$ resolution and $1 \mathrm{~cm} / \mathrm{s}$ scan speed. The number of scans for each spectrum was 32. All spectra were collected within the range of $4000-650 \mathrm{~cm}^{-1}$ wave number. The sampling crystal was cleaned and finally dried under nitrogen gas flow after each measurement. The measurements were repeated at least three times.

Statistical Analysis of FTIR: Spectral data was analyzed by using multivariate statistical techniques with SIMCA software (SIMCA P-10.5 Umetrics Inc. Sweden). Partial least square (PLS) regression was applied to hydrolysates of fruit pomaces to predict the concentration of several sugars (arabinose, glucose, galactose, fructose, xylose, cellobiose), soluble solids, reducing sugar content using whole spectral range.

\subsection{Experimental Design and Statistical Analysis}

The experimental design consisted of two stages; screening and optimization. In the screening experiments, the effect of temperature $\left({ }^{\circ} \mathrm{C}\right)$, time $(\mathrm{min})$, percent phosphoric acid concentration $(\mathrm{v} / \mathrm{v})$ and solid (dry fraction of 
pomace):liquid (solid fraction of pomace + added liquid) ratio (g:ml) represented as $\mathrm{S}: \mathrm{L}$ ratio on the hydrolysis of fruit pomaces were evaluated by $2^{4}$ factorial design with five replicates of the centerpoints using Design Expert Version 7.0 statistical software. The response variable was total reducing sugar yield (RSY) of the hydrolysis expressed in percentages. In the optimization experiments response surface method was used by applying central composite design, based on the results obtained in the screening experiments. Here, the factor variables were determined as acid concentration and solid:liquid ratio (S:L). Temperature was set at $126{ }^{\circ} \mathrm{C}$ for apricot and orange and at $110^{\circ} \mathrm{C}$ for peach and apple pomaces. Similarly, time was fixed at $20 \mathrm{~min}$ for orange and $40 \mathrm{~min}$ for other pomaces. The levels and factors of screening and optimization are tabulated in Table I.

Analysis of data and generation of response surface graphics were done by Design Expert Version 7. After running the experiments and measuring RSY, a second order model including interactions was fitted to the response data:

$$
Y=\beta_{0}+\sum_{i=1}^{k} \beta_{i} X_{i}+\sum_{i=1}^{k} \beta_{i i} X_{i}^{2}+\sum_{i} \sum_{j} \beta_{j} X_{i} X_{j}+\varepsilon
$$

where $Y$ is the predicted response, $k$ is the number of factor variables, $\beta_{0}$ is the model constant, $\beta_{i}$ is linear coefficient, $\beta_{i i}$ is the quadratic coefficient, $\beta_{i j}$ is the interaction coefficient. $X_{i}$ is the factor variable in its coded form. The following equation was used in order to determine the coded variable $(X)$ :

$$
\begin{aligned}
X= & {[\text { actual }-(\text { low-level }+ \text { high-level }) / 2] / } \\
& (\text { high-level }- \text { low-level }) / 2
\end{aligned}
$$

\subsection{Fermentation}

Fermentation was carried out in two steps; aerobic pregrowing step and anaerobic bioethanol production step.

Pre-growing step: Two media were used for aerobic growth; a rich medium (yeast-peptone-malt extract; YPM) as described by Skory et al. ${ }^{23}$ and a minimal medium (yeast nitrogen base medium; YNB) as described by Wickerham and Burton. ${ }^{24}$ These two media (three replicates for each) were inoculated with conidia $\left(\sim 1 \times 10^{7}\right)$, and incubated at $30{ }^{\circ} \mathrm{C}$ at $170 \mathrm{rpm}$ for two days. Mycelia and spores were extracted aseptically by centrifugation ( $3000 \mathrm{~g}$ for $15 \mathrm{~min}$ ) and added to the hydrolysates in order to start the anaerobic part of the fermentation (bioethanol production step).

Bioethanol production step: Apple pomace hydrolysate was chosen as the fermentation medium. According to the optimization results, temperature of $110{ }^{\circ} \mathrm{C}, 40 \mathrm{~min}-$ utes and $4 \%$ acid was chosen as the hydrolysis conditions. $1 \mathrm{~g} / 10.5 \mathrm{ml}$ solid-liquid ratio was chosen to get at least $\sim 25 \mathrm{~g} / \mathrm{L}$ sugar in the hydrolysates. Hydrolysates were filtered, neutralized to $\mathrm{pH} 4.5$ by $\mathrm{NaOH}$, filtered again, sterilized at $121{ }^{\circ} \mathrm{C}$ for $15 \mathrm{~min}$. Forty $\mathrm{ml}$ of hydrolysate was added into $50 \mathrm{ml}$ flasks in order to leave $\sim 20 \%$ of the culture flask volume as air space. After aseptic inoculation, plastic paraffin film was used to seal the flask and a silicone-tubing $(1.6 \times 1.6=4.8 \mathrm{~mm})$, packed tightly with cotton was vented trough the paraffin film. Flasks were incubated either statically in a standard or a $\mathrm{CO}_{2}$ incubator (to compare the effect of fully anaerobic and partially anaerobic conditions), or were shaken at $170 \mathrm{rpm}$ in a standard incubator. The incubation temperature for each incubator $\left(\mathrm{CO}_{2}\right.$, shaking and static) was set to $30{ }^{\circ} \mathrm{C}$. First sample was taken on the fourth day and proceeding samples were taken daily until the 14th day. Bioethanol, main sugars (xylose, galactose, mannose and arabinose) furfural and HMF in samples were determined by HPLC. Reducing sugars were determined according to Nelson-Somogyi ${ }^{22}$ method and data were reported as the averages of three measurements.

\section{RESULTS AND DISCUSSION}

\subsection{Results of Chemical Compositional Analysis of Fruit Pomaces}

According to the chemical compositional analysis (Table II), orange pomace had the highest initial reducing sugar $(33.89 \%)$, followed by peach and apricot $(\sim 22 \%)$ and the lowest being for apple $(6.25 \%)$. On the other hand, apple pomace had the highest total solid content, which suggested that it might have higher sugar content after a pretreatment since it contains cellulose, hemicellulose and lignin in its solid fraction. In fact this was confirmed by the total dietary fiber content being the highest among the others. According to the HPLC results glucose and fructose were identified as the dominant sugars in orange, peach and apricot (data not shown) whereas; arabinose was the main sugar in apple pomace. (An example for a typical HPLC chromatogram is presented in Fig. 1 for apple pomace hydrolysate.) The presence of fermentable sugars in significant amounts together with proteins can serve as essential nutrients for the growth of microorganisms and place pomaces as potential candidates to be used for this purpose. In fact the composition of pomaces can vary according to fruit variety used and the type of the process applied for juice extraction. ${ }^{25}$ Nevertheless, as it is evident from Table II, considering overall the chemical components of the fruit pomaces, they definitely posses certain potential for various industrial fermentations especially involving fungal organism due to their low water activity content and complex nature.

\subsection{Statistical Analysis of the Experimental Results}

The screening and optimization results of the process parameters for the pretreatment of various pomaces with the response variable as the total reducing sugar yield (RSY) of the hydrolysis (expressed in percentage) are 
Table II. Compositional analysis of fruit pomaces (\%).*

\begin{tabular}{|c|c|c|c|c|}
\hline & Peach & Apple & Apricot & Orange \\
\hline Soluble ash in wet weight & $0.36 \pm 0.00$ & $0.06 \pm 0.01$ & $0.6 \pm 0.1$ & $0.3 \pm 0.00$ \\
\hline Soluble ash in dry weight & $2.15 \pm 0.00$ & $0.22 \pm 0.04$ & $3.34 \pm 0.1$ & $1.59 \pm 0.07$ \\
\hline Insoluble ash in wet weight & $0.09 \pm 0.00$ & $0.22 \pm 0.01$ & $0.19 \pm 0.1$ & $0.35 \pm 0.00$ \\
\hline Insoluble ash in dry weight & $0.54 \pm 0.00$ & $0.82 \pm 0.04$ & $1.12 \pm 0.1$ & $1.89 \pm 0.07$ \\
\hline Total ash in wet weight & $0.45 \pm 0.00$ & $0.28 \pm 0.00$ & $0.79 \pm 0.01$ & $0.65 \pm 0.02$ \\
\hline Total ash in dry weight & $2.69 \pm 0.01$ & $1.04 \pm 0.01$ & $4.47 \pm 0.1$ & $3.49 \pm 0.2$ \\
\hline Protein & $1.31 \pm 0.05$ & $1.9 \pm 0.20$ & $1.29 \pm 0.01$ & $1.54 \pm 0.3$ \\
\hline Total solids & $16.69 \pm 0.2$ & $27.53 \pm 0.1$ & $17.75 \pm 0.5$ & $18.81 \pm 0.5$ \\
\hline Soluble solids & $8.09 \pm 0.07$ & $2.23 \pm 0.03$ & $10.74 \pm 0.06$ & $11.53 \pm 0.2$ \\
\hline Insoluble solids & $8.59 \pm 0.07$ & $25.30 \pm 0.03$ & $7 \pm 0.06$ & $7.28 \pm 0.2$ \\
\hline Total dietary fiber & $18.28 \pm 1.5$ & $32.54 \pm 0.5$ & $14.6 \pm 1.0$ & $13.9 \pm 1.5$ \\
\hline Soluble dietary fiber** & $13.85 \pm 2.0$ & $11.24 \pm 0.2$ & $11.32 \pm 1.5$ & $8.40 \pm 1.0$ \\
\hline Insoluble dietary fiber** & $7.06 \pm 1.2$ & $25.24 \pm 1.0$ & $5.86 \pm 2.5$ & $8.61 \pm 0.5$ \\
\hline Water activity $\left(\mathrm{a}_{w}\right)$ & $0.89 \pm 0.01$ & $0.84 \pm 000$ & $0.87 \pm 0.01$ & $0.83 \pm 0.00$ \\
\hline Initial reducing sugar & $22.08 \pm 0.00$ & $6.25 \pm 0.01$ & $22.91 \pm 0.02$ & $33.89 \pm 0.03$ \\
\hline
\end{tabular}

Notes: *Replicate numbers were given in materials and methods section; ${ }^{* *}$ Involves protein (Dietary fiber $=$ solid - ash + protein).

presented in Table III. All the screening and optimization results are discussed below for each pomace, independently. Four verification experiments were carried out at the predicted optimum conditions for apple, orange and peach pomaces.

\subsubsection{Screening and Optimization of Process Variables for the Dilute Acid Hydrolysis of Apple Pomace}

The screening and optimization results for the dilute acid hydrolysis of apple pomace are presented in the ANOVA table (Table IV(a)), which indicated that, the model for screening part was highly significant at high confidence level ( $p$-value $<0.0001)$. This was evident from the low probability $p$-values and computed $F$-values, which are statistically valid measures of how well the factors describe the variation in the mean of data. These values suggested that the factors explain adequately the variation in the data about its mean, and the estimated factor effects were in fact real. According to this table, the factors significantly affecting the RSY in the screening step were time $\left(X_{4}\right)$ and the interaction of time and temperature $\left(X_{34}\right)$ followed by temperature $\left(X_{3}\right)$ ( $p$-value $\left.<0.05\right)$. The effect of S:L ratio $\left(X_{1}\right)$ and acid concentration $\left(X_{2}\right)$ were not significant ( $p$-value $>0.05)$ on the RSY, however according to our experience it is known that $X_{1}$ and $X_{2}$ were important factors that should not be eliminated but their investigated levels should be revised. Therefore $X_{1}$ and $X_{2}$ were added

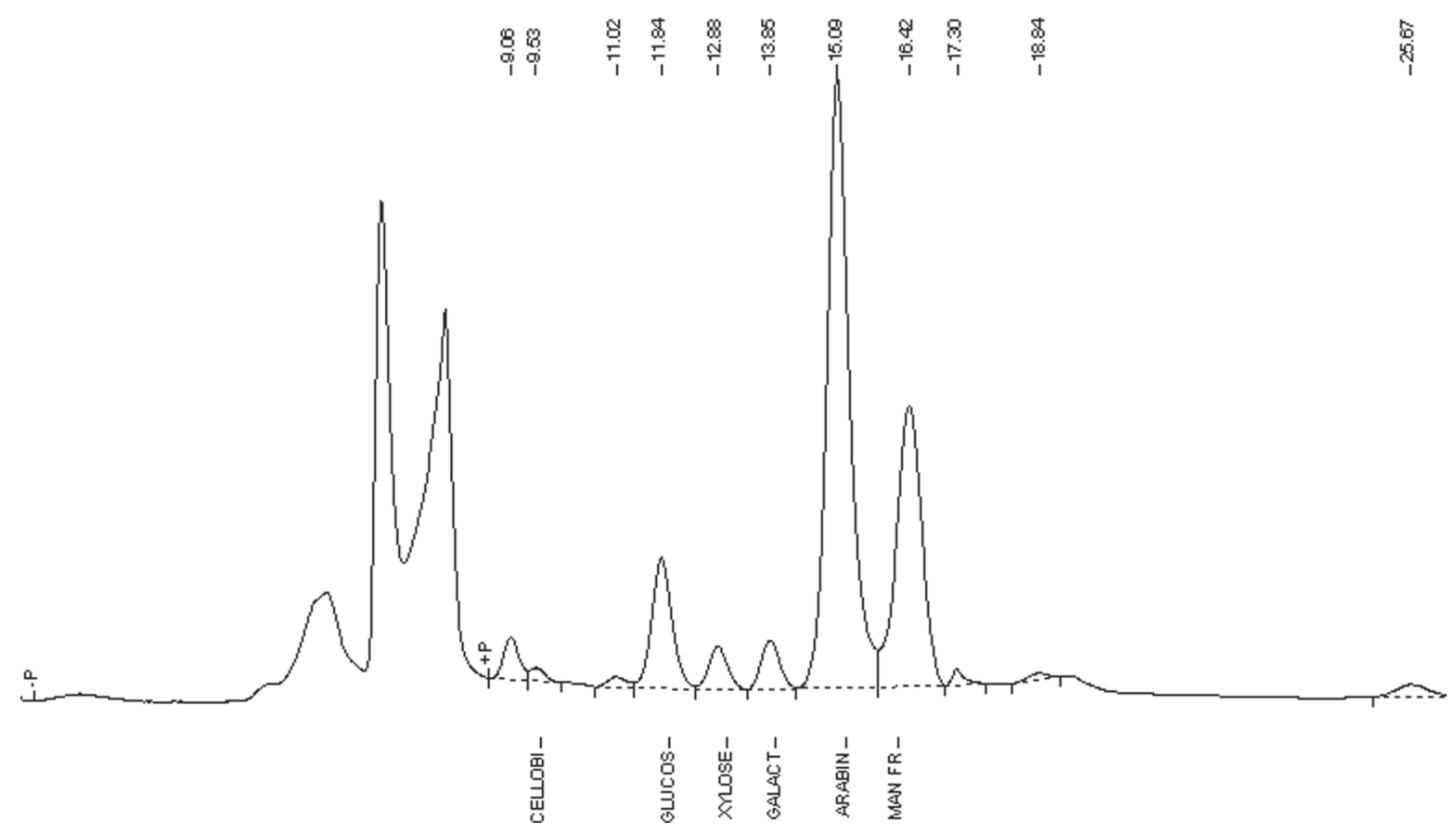

Fig. 1. An example of the HPLC chromotogram of apple pomace hydrolysate treated with 1:7 Solid:liquid ratio, $\% 3$ asid, $110{ }^{\circ} \mathrm{C}$ and 20 min. 
Table III. Screening and optimization results of the pomaces with respect to RSY (\%) as response.

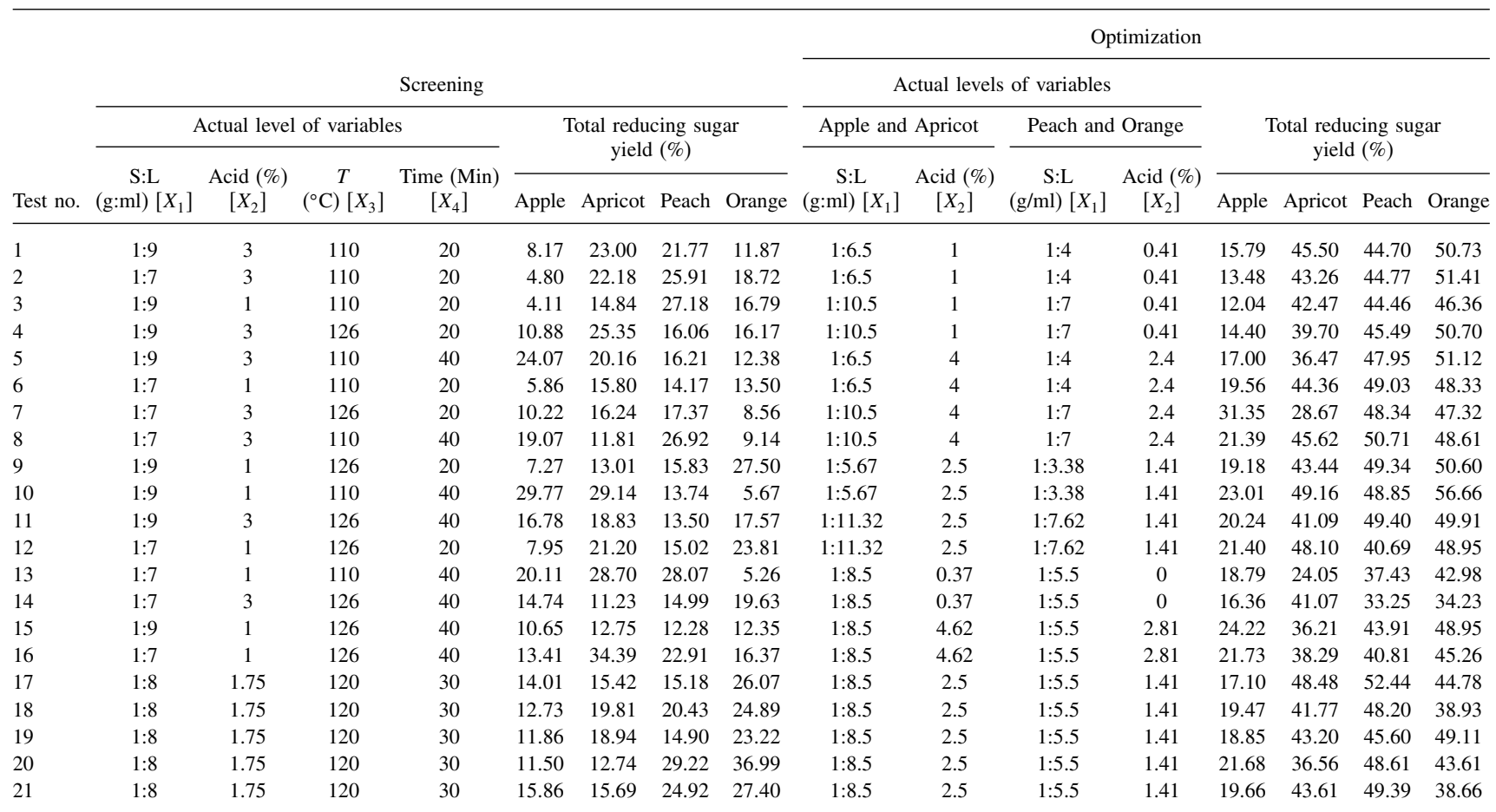

to the model and their new levels were decided for the optimization step. The $R$-squared value of this screening model indicated that $88.6 \%$ of the total variables were explained by the model.

The plot of the interaction between $X_{3}$ and $X_{4}$ indicated that at the levels of $110{ }^{\circ} \mathrm{C}$ and $40 \mathrm{~min}$, RSY was explicitly high (Fig. 2(a)). Therefore, $X_{3}$ and $X_{4}$ parameters of the process were fixed at these levels in the optimization of apple pomace. As can be seen in Figure 2(a), RSY production reduced dramatically at $126^{\circ} \mathrm{C}$ for $40 \mathrm{~min}$., which is a relatively harsh condition. This is probably due to the conversion of the fruit sugars into secondary metabolites other than HMF under excess time and temperature. This fact revealed the importance of the investigation of the interactions between the factors. Considering $X_{1}$ and $X_{2}$, there was only a slight increase in the RSY at the lower ratio of $X_{1}(1 \mathrm{~g} / 9 \mathrm{ml})$ and higher concentration of $X_{2}(3 \%)$ at the fixed values of $110{ }^{\circ} \mathrm{C}$ and $40 \mathrm{~min}$ (data not shown). Therefore, the level of $X_{1}$ was enlarged towards the lower ratios, whereas the levels of $X_{2}$ were enlarged towards the higher concentrations for the optimization step.

The ANOVA results of response surface model (optimization) demonstrated that the model was significant due to a $p$-value of 0.0014 . It was seen that (Table IV(a)) $X_{2}$ has an important effect on the RSY with a very low $p$-value (0.0006). Additionally, it had strong interaction with the $X_{1}$ between the investigated levels. Final equation in terms of coded factors is given below.

RSY of apple pomace $=+19.37+0.79^{*} X_{1}$

$$
+3.05^{*} X_{2}+2.38^{*} X_{12}
$$

According to the response surface plot (Fig. 2(c)) the optimized conditions to obtain high amount of RSY were at higher concentrations of $X_{2}(4 \%)$ and lower ratios of $X_{1}(1 \mathrm{~g} / 10.5 \mathrm{ml})$. It should be noted that acid concentrations higher than $4 \%$ may lead to decomposition of liberated sugars through the secondary reactions and cause the formation of furfural and HMF, which is not desired for microbial fermentations. ${ }^{26,27}$ Moreover, lower S:L ratio $(<1 \mathrm{~g} / 0.5 \mathrm{ml})$ may require excessive volume in the process area, increasing the cost of the process. The increase of RSY at these levels might probably be due to the effective diffusion of acid through the solid part of the hydrolysate. The current study achieved a 5 fold increase from initial reducing sugar of $6.25 \%$ to $31.35 \%$ RSY, as a result of screening and optimization steps. In a citric acid production study performed by Song et al. ${ }^{28}$ reducing sugar level of $36.3 \%$ could be achieved under the optimum conditions after an enzymatic hydrolysis (by cellulase) of the apple pomace, whose initial reducing sugar was $19.22 \%$. Furthermore Ma et al. ${ }^{29}$ also studied cellulase pretreatment of apple pomace and achieved $27.7 \%$ net increase of reducing sugars. Dilute-acid hydrolysis of apple pomace is an effective treatment prior to enzymatic hydrolysis since the cost of enzymes are higher and the time required for acid hydrolysis is much lower than that for enzymatic reactions. ${ }^{30}$

The maximum sugar yield (around 36.3\% with 5 fold increase) in the current study is very promising, considering that mild conditions were used without the formation of inhibitory compounds. 
Table IV. Analysis of variance (ANOVA) for screening and optimization of apple, orange and peach hydrolysates.

\begin{tabular}{|c|c|c|c|c|c|c|c|c|c|c|c|}
\hline \multicolumn{6}{|c|}{ Screening } & \multicolumn{6}{|c|}{ Optimization } \\
\hline Source & Sum of squares & df & Mean square & $F$ value & $\begin{array}{c}p \text {-value } \\
\text { Prob }>F\end{array}$ & Source & Sum of squares & $\mathrm{df}$ & Mean square & $F$ value & $\begin{array}{l}p \text {-value } \\
\text { Prob }>F\end{array}$ \\
\hline \multicolumn{12}{|c|}{ (a) Apple pomace } \\
\hline Model & 717.32 & 5 & 143.46 & 19.95 & $<0.0001$ & Model & 204.28 & 3 & 68.09 & 8.13 & 0.0014 \\
\hline$X_{1}$ & 15.10 & 1 & 15.10 & 1.03 & 0.1694 & $X_{1}$ & 9.88 & 1 & 9.88 & 1.18 & 0.2927 \\
\hline$X_{2}$ & 5.78 & 1 & 5.78 & 0.39 & 0.3853 & $X_{2}$ & 149.23 & 1 & 149.23 & 17.81 & 0.0006 \\
\hline$X_{3}$ & 36.18 & 1 & 110.07 & 2.47 & 0.0416 & $X_{12}$ & 45.17 & 1 & 45.17 & 5.39 & 0.0329 \\
\hline$X_{4}$ & 498.82 & 1 & 36.18 & 34.06 & $<0.0001$ & Residual & 142.42 & 17 & 8.38 & & \\
\hline$X_{34}$ & 161.44 & 1 & 498.82 & 11.02 & 0.0003 & Lack of fit & 59.18 & 5 & 11.84 & 1.71 & 0.2077 \\
\hline Curvature & 0.15 & 1 & 0.15 & 0.022 & 0.8855 & Pure error & 83.24 & 12 & 694 & & \\
\hline Residual & 205.06 & 14 & 7.19 & & & Cor total & 346.70 & 20 & & & \\
\hline Lack of fit & 88.05 & 10 & 8.81 & 2.79 & 0.1677 & & & & & & \\
\hline Pure error & 12.64 & 4 & 3.16 & & & & & & & & \\
\hline Cor total & 818.16 & 20 & & & & & & & & & \\
\hline Std. dev. & 2.68 & \multicolumn{3}{|c|}{$R$-squared } & 0.88 & Std. dev. & \multicolumn{2}{|l|}{2.89} & \multicolumn{2}{|c|}{$R$-squared } & 0.59 \\
\hline Mean & 13.04 & \multicolumn{3}{|c|}{ Adj $R$-squared } & 0.83 & Mean & 19.37 & & \multicolumn{2}{|c|}{ Adj $R$-squared } & 0.52 \\
\hline C. V. $\%$ & 20.57 & \multicolumn{3}{|c|}{ Pred $R$-squared } & 0.70 & C. V. $\%$ & 14.95 & & \multicolumn{2}{|c|}{ Pred $R$-squared } & 0.27 \\
\hline PRESS & 245.16 & \multicolumn{3}{|c|}{ Adeq precision } & 13.35 & PRESS & 253.62 & & \multicolumn{2}{|c|}{ Adeq precision } & 8.60 \\
\hline \multicolumn{12}{|c|}{ (b) Orange pomace } \\
\hline Model & 374.29 & 5 & 74.86 & 3.41 & 0.0319 & Model & 304.75 & 3 & 101.58 & 7.70 & 0.0018 \\
\hline$X_{1}$ & 1.77 & 1 & 1.77 & 0.081 & 0.7804 & $X_{1}$ & 26.22 & 1 & 26.22 & 1.99 & 0.1767 \\
\hline$X_{2}$ & 3.25 & 1 & 3.25 & 0.15 & 0.7062 & $X_{2}$ & 25.55 & 1 & 25.55 & 1.94 & 0.1821 \\
\hline$X_{3}$ & 147.89 & 1 & 147.89 & 6.74 & 0.0212 & $X_{1}^{2}$ & 252.99 & 1 & 252.99 & 19.17 & 0.0004 \\
\hline$X_{4}$ & 92.68 & 1 & 92.68 & 4.22 & 0.0591 & Residual & 224.38 & 17 & 13.20 & & \\
\hline$X_{24}$ & 128.71 & 1 & 128.71 & 5.86 & 0.0296 & Lack of fit & 69.81 & 5 & 13.96 & 1.08 & 0.4171 \\
\hline Curvature & 644.52 & 1 & 0.15 & 44.5 & $<0.0001$ & Pure error & 154.56 & 12 & 12.88 & & \\
\hline Residual & 307.33 & 14 & 7.19 & 21.95 & & Cor total & 529.13 & 20 & & & \\
\hline Lack of fit & 190.31 & 10 & 8.81 & 19.03 & 0.7356 & & & & & & \\
\hline Pure error & 117.02 & 4 & 3.16 & 29.25 & & & & & & & \\
\hline Cor total & 1326.14 & 20 & & & & & & & & & \\
\hline Std. dev. & 4.69 & \multicolumn{3}{|c|}{$R$-squared } & 0.55 & Std. dev. & \multicolumn{2}{|l|}{3.63} & \multicolumn{2}{|c|}{$R$-squared } & 0.57 \\
\hline Mean & 17.80 & \multicolumn{3}{|c|}{ Adj $R$-squared } & 0.39 & Mean & \multicolumn{2}{|l|}{47.02} & Adj $R$-sc & uared & 0.50 \\
\hline C. V. $\%$ & 26.32 & & Pred $R$-squared & & 0.49 & C. V. $\%$ & 7.73 & & Pred $R$-s & quared & 0.35 \\
\hline PRESS & 670.03 & & Adeq precision & & 7.83 & PRESS & 338.85 & & Adeq pre & cision & 8.10 \\
\hline & & & & & (c) Peacl & pomace & & & & & \\
\hline Model & 315.16 & 5 & 63.19 & 2.87 & 0.0548 & Model & 281.10 & 3 & 93.70 & 10.20 & 0.0004 \\
\hline$X_{1}$ & 51.88 & 1 & 51.88 & 2.36 & 0.1471 & $X_{1}$ & 4.96 & 1 & 4.96 & 0.54 & 0.4726 \\
\hline$X_{2}$ & 0.78 & & 0.78 & 0.035 & 0.8537 & $X_{2}$ & 83.11 & 1 & 83.11 & 9.05 & 0.0079 \\
\hline$X_{3}$ & 132.29 & 1 & 132.29 & 6.01 & 0.0280 & $X_{2}^{2}$ & 193.04 & 1 & 193.04 & 21.01 & 0.0003 \\
\hline$X_{4}$ & 1.37 & 1 & 1.37 & 0.062 & 0.8064 & Residual & 156.17 & 17 & 9.19 & & \\
\hline$X_{14}$ & 129.61 & 1 & 129.61 & 5.88 & 0.0294 & Lack of fit & 76.43 & 5 & 15.29 & 2.30 & 0.1101 \\
\hline Curvature & 16.20 & 1 & 16.20 & 0.74 & 0.4056 & Pure error & 79.74 & 12 & 6.65 & & \\
\hline Residual & 308.38 & 14 & 22.03 & & & Cor total & 437.27 & 20 & & & \\
\hline Lack of fit & 154.00 & 10 & 15.40 & 0.40 & 0.8912 & & & & & & \\
\hline Pure error & 154.38 & 4 & 38.59 & & & & & & & & \\
\hline Cor total & 640.51 & 20 & & & & & & & & & \\
\hline Std. dev. & 4.69 & & $R$-squared & & 0.51 & Std. dev. & 3.03 & & $R$-squa & red & 0.64 \\
\hline Mean & 19.36 & & Adj $R$-squared & & 0.33 & Mean & 45.87 & & Adj $R$-sq & uared & 0.57 \\
\hline C. V. $\%$ & 24.24 & & Pred $R$-squared & & 0.008 & C. V. $\%$ & 6.61 & & Pred $R$-s & uared & 0.42 \\
\hline PRESS & 635.46 & & Adeq precision & & 5.72 & PRESS & 252.21 & & Adeq pre & cision & 9.14 \\
\hline
\end{tabular}

\subsubsection{Screening and Optimization of Process Variables for the Dilute Acid Hydrolysis of Orange Pomace}

According to ANOVA table (Table IV(b)) a $p$-value of 0.0319 implied that the model of screening step was significant and only $X_{3}$ as a linear term and $X_{24}$ as an interactive term were significant terms based on their low $p(p$-value $<0.05)$ values. Similar to the screening of apple pomace, the effect of $X_{1}$ and $X_{2}$ were not significant $(p$-value $>0.05)$ on the RSY, however $X_{1}$ and $X_{2}$ were 
Dilute-Acid Hydrolysis of Apple, Orange, Apricot and Peach Pomaces as Potential Candidates

Ucuncu et al.
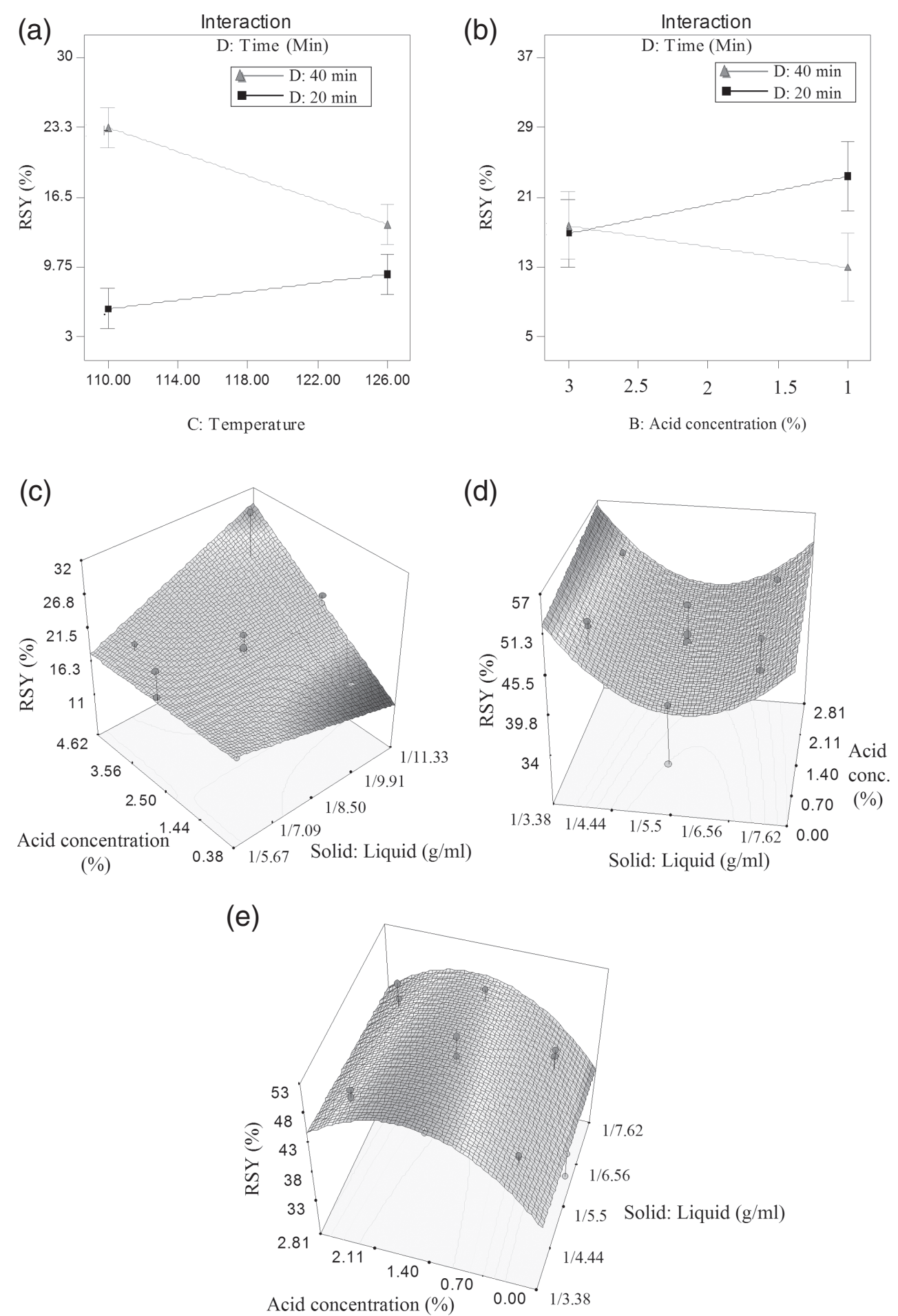

Fig. 2. The interaction graph of time and temperature in the screening process of apple pomace (a), the interaction graph of time and acid concentration in the screening of orange pomace (b) and response surface plots of apple, orange and peach pomace (c)-(e) (RSY replicate numbers were given in materials and methods section).

added to the model based on similar discussions provided previously. Therefore, their new levels were revised in the optimization step.

One factor plot of temperature indicated that $126^{\circ} \mathrm{C}$ led to high RSY (not shown). Moreover, higher RSY could be obtained at $1 \%$ acid concentration and 20 min according to the plot (Fig. 2(b)) showing the interaction of time and acid ratio $\left(X_{24}\right)$ at $126{ }^{\circ} \mathrm{C}$, and $1 \mathrm{~g} / 8 \mathrm{ml} \mathrm{S}: \mathrm{L}$ ratio. In fact, RSY level was lower when orange pomace was treated with higher concentration of acid (3\%) for $20 \mathrm{~min}$ 
(Fig. 2(b)). The interaction between the acid concentration and time was not so pronounced at higher acid concentrations compared to lower concentrations. This revealed that sugars of orange pomace were converted into reducing sugars at higher concentrations at shorter time and longer time did not effect the RSY value. However, at lower acid concentration time factor was significant on the hydrolysis and the mild conditions as $(1 \%$ and $20 \mathrm{~min})$ lead to the highest RSY. Prolonging the time at this acid concentration possibly led to the formation of side products (not assayed) formed from reducing sugars. Furthermore, there was only a slight decrease of RSY at the lower S:L ratio $(1 \mathrm{~g} / 9 \mathrm{ml})$ in comparison with the higher ratio of $X_{1}(1 \mathrm{~g} / 7 \mathrm{ml})$. Therefore in the optimization step, $X_{3}$ and $X_{4}$ were fixed and $X_{1}$ and $X_{2}$ were extended as shown in Table I.

The ANOVA results of the response surface model (optimization) demonstrated that the model was significant due to a $p$-value of 0.0018 . None of the single factors showed significant effect on the model. However, quadratic effect of S:L ratio $\left(X_{1}^{2}\right)$ was highly significant with a $p$-value of 0.0004 . Final equation in terms of coded factors is given below.

RSY of orange hydrolysates

$$
=+43.49-1.28 * X_{1}+1.26 * X_{2}+4.63 * X_{12}
$$

From Table III it is observed that the 10th experiment showed the highest RSY $(56.66 \%)$ under the conditions of $126^{\circ} \mathrm{C}, 20 \mathrm{~min}, 1 \mathrm{~g} / 3.38 \mathrm{ml} \mathrm{S}: \mathrm{L}$ ratio and $2.81 \%$ acid concentration. This corresponded to 1.67 fold increase considering the initial reducing sugar content of orange pomace (33.89\%, Table II). Based on these, it can be deduced that the screening and optimization steps in fact increased the RSY. Talebnia et al. ${ }^{31}$ studied orange peel saccharification by dilute sulphuric acid hydrolysis and found the optimum conditions as $116{ }^{\circ} \mathrm{C}, 0.5 \%$ sulphuric acid, $6 \%$ solid concentration and $12.9 \mathrm{~min}$, leading to $41.8 \%$ total sugars and 2.6\% HMF. Furthermore, the study indicated that higher temperatures $\left(140,180\right.$ and $210{ }^{\circ} \mathrm{C}$ ) did not improve the yield of total sugar values of orange peel, since hydrolysis of pectin and galacturonic acid could not be detected. Similarly, an increase in total solid concentration led to decrease of RSY. Although there was an increase in RSY at low levels of solid concentration in the current study, it was found out that high $\mathrm{S}: \mathrm{L}$ ratio $(1 \mathrm{~g} / 3.38 \mathrm{ml})$ resulted in higher RSY, leading to less volume space, low cost and easier operation of the process. Although an increase in the acid level from 0 to $2.81 \%$ (at high $\mathrm{S}: \mathrm{L}$ ratio, $1 \mathrm{~g} / 3.38 \mathrm{ml}$ ) was slightly effective in releasing sugars from both hemicellulosic and cellulosic fraction of orange pomace, this did not show a critical significance as depicted in the Figure 2(d). $X_{1}^{2}$ (due to its quadratic nature of the plot) turned out to be the major factor affecting the hydrolysis positively. It should be noted that higher $\mathrm{S}: \mathrm{L}$ ratios than $1 \mathrm{~g} / 3 \mathrm{ml}$ may not be feasible, since the liquid fraction is not extractable from the hydrolyzed material. ${ }^{32}$

\subsubsection{Screening and Optimization of Process Variables for the Dilute Acid Hydrolysis of Peach Pomace}

Since the model obtained from the screening study was not significant (Table IV(c)), the ANOVA table could not be used as the basis for the determination of the factors for the optimization step. Instead single runs presented in Table III were analyzed in order to determine the important factors for the optimization step. For example, the highest sugar conversion $(29.22 \%)$ was obtained in 20 th run, in which the conditions were $120{ }^{\circ} \mathrm{C}, 30 \mathrm{~min}, 1 \mathrm{~g} / 8 \mathrm{ml} \mathrm{S}: \mathrm{L}$ ratio and $1.75 \%$ acid concentration. There was only a slight difference between the RSY of 20th and 13th experiment, therefore the conditions of 13th was preferred with respect to its lower acid concentration and temperature. Based on these, the temperature and time $\left(X_{3}\right.$ and $\left.X_{4}\right)$ were fixed at $110{ }^{\circ} \mathrm{C}$ and $40 \mathrm{~min}$ for the optimization step and $X_{1}$ and $X_{2}$ were enlarged as in Table I.

It can be clearly deduced from the ANOVA table (Table IV(c)) of the optimization step and response surface graph presenting the interaction of $X_{1}$ and $X_{2}$ (Fig. 2(e)), that $\mathrm{S}: \mathrm{L}$ ratio $\left(X_{1}\right)$ did not play an important role on the RSY. This can be considered as an advantage for a hydrolysis process, because the fruit pomace batches supplied to fruit juice manufacturer may show variation in the requirement for S:L ratios, due to the seasonal and/or operational differences. Therefore, any S:L ratio between the ranges investigated can be combined with an acid concentration of $1.7 \%$ in order to obtain a maximum RSY. Final equation in terms of coded factors is given below.

RSY of peach hydrolysates

$$
=+48.96-0.56 * X_{1}+2.28 * X_{2}-4.04 * X_{2}^{2}
$$

As a result the decisive factor on RSY for the hydrolysis of peach pomace is the concentration of the acid used ( $p$-value 0.0079). To best of our knowledge there isn't any literature on the peach pomace hydrolysis in order to compare the results of the current study. That's why these results will serve as an initial study contributing to the literature and closing the gap to some degree.

\subsubsection{Screening and Optimization of Process Variables for the Dilute Acid Hydrolysis of Apricot Pomace}

According to the ANOVA results of apricot pomace (not given) in the screening step, single factors had no significant effect on the model, which was different from screening results of other pomaces. Temperature was significant in the form of interaction $\left(X_{123}\right)$ with a $p$-value of 0.0236 unlike the results of other pomaces, where temperature has been significant as a single factor. Indeed, Talebnia et al. ${ }^{31}$ determined that temperature together with acid concentration showed highly significant effect on optimization of citrus wastes saccharification by dilute-acid hydrolysis. Here, acid concentration on the contrary had no single 
significant effect but was significant in the form of interactions with other factors $\left(X_{12}, X_{24}\right.$ and $\left.X_{123}\right)$. The model, significant with a probability value of 0.0053 was reliable due to high coefficients and non significant Lack of Fit $\left(R^{2}=0.85\right)$ value.

The highest RSY (34.39\%) was obtained under the conditions described in the 16th experiment $\left(1 \mathrm{~g} / 7 \mathrm{ml} X_{1}, 1 \%\right.$ $X_{2}, 126{ }^{\circ} \mathrm{C}$ and $40 \mathrm{~min}$ ) (Table III). Higher temperature showed higher RSY in many experimental runs similar to longer exposure times. Moreover, the interactive terms involving time were highly significant. Therefore, in the optimization step, temperature and time factors were fixed at $126{ }^{\circ} \mathrm{C}$ and $40 \mathrm{~min}$, respectively. Both low and high levels of $X_{1}$ and $X_{2}$ showed an increase in RSY whereas the centerpoints of these two factors led to decrease in RSY. In order to determine if there were higher responses beyond the levels studied in the screening step, the levels of $X_{1}$ and $X_{2}$ were expanded in the optimization step (Table I). In the optimization study of apricot pomace a significant model could not be obtained, since none of the factors and neither their first or second order interactions showed significant effect on the model. The reason of this might be that the responses were close to each other. The range of the obtained results was $24 \%$ at minimum and $49 \%$ at maximum and more importantly these results were predominantly located between 41.25 and $43.75 \%$. Nevertheless, in the 10th experiment, the highest yield of RSY (49.16\%), which was 1.42 times higher than the maximum RSY (34.39\%) of screening step (16th run), was achieved under the conditions at which $126^{\circ} \mathrm{C}, 40 \mathrm{~min}, 1 \mathrm{~g} / 5.67 \mathrm{ml}$ $\mathrm{S}: \mathrm{L}$ ratio and $2.5 \%$ acid were applied. Even though a significant model could not be obtained, the RSY values were satisfactory that allows the producer to work with a tolerable range of $S: L$ ratio of the pomace and acid concentration. This is an important point thus there is a strong possibility that the supplied pomaces may have variable solid-liquid ratio due to the differences in the fruit manufacturers and seasonal factors.

In order to validate the adequacy of the model equations a total of 4 verification experiments were carried out at the predicted optimum conditions for orange, apple and peach pomaces (Table V). The overall margin of error was $14.47 \%$ for apple pomace, $15.21 \%$ for peach pomace and $15.87 \%$ for orange pomace.

Overall the screening and optimization study for individual pomaces indicated that the hydrolysis condition for each pomace has to be specified independently and can vary according to the source of the pomace. Therefore, the results of this study can be very informative for manufacturer of fermentation industry, who would like to make use of these pomaces. Besides, this study also demonstrates the fermentative potential of pomaces due to their high RSY obtained from the optimized dilute acid hydrolysis. Also it provides an alternative solution for waste treatment of pomaces and creates an economical return.
Table V. Validation experiments at the predicted optimum conditions for apple, orange and peach pomaces.

\begin{tabular}{cccccc}
\hline \multirow{6}{*}{ Apple } & \multicolumn{3}{c}{$\begin{array}{c}\text { Estimated sugar } \\
\text { conversion } \\
(\%)\end{array}$} & $\begin{array}{c}\text { Actual sugar } \\
\text { conversion } \\
(\%)\end{array}$ & $\begin{array}{c}\text { Error } \\
(\%)\end{array}$ \\
\hline \multirow{6}{*}{ Orange } & $1 / 6.5$ & 2.19 & 18.44 & 16.38 & 12.68 \\
& $1 / 8.6$ & 2.97 & 20.40 & 17.15 & 15.93 \\
& $1 / 9.3$ & 1.08 & 15.84 & 13.32 & 15.90 \\
& $1 / 9.0$ & 3.91 & 23.10 & 20.01 & 13.37 \\
& $1 / 6.8$ & 2.26 & 47.12 & 40.46 & 14.13 \\
& $1 / 5.9$ & 0.87 & 42.84 & 37.66 & 12.09 \\
Peach & $1 / 4.0$ & 2.38 & 50.35 & 41.23 & 18.11 \\
& $1 / 4.1$ & 2.24 & 49.51 & 40.01 & 19.18 \\
& $1 / 5.2$ & 1.79 & 49.25 & 40.02 & 18.74 \\
& $1 / 6.3$ & 2.38 & 46.82 & 40.66 & 13.15 \\
& $1 / 6.4$ & 0.55 & 43.40 & 38.01 & 12.41 \\
& $1 / 4.2$ & 0.60 & 46.87 & 39.11 & 16.55 \\
\hline
\end{tabular}

\subsection{Analysis of Hydrolysates}

Furfural and HMF: Furfural and HMF are decomposition products of pentoses and hexoses. The formation of furfural is a first-order reaction, where both temperature and acid concentration affects the reaction constant. On the other hand formation of HMF during dilute-acid hydrolysis consists of sequential reactions. The first reaction involves the hydrolysation of cellulose and hemicellulose to hexose monomers, where the second reaction involves decomposition of liberated hexoses to HMF. According to Saeman, ${ }^{33}$ these two reactions, which are influenced by temperature and acid concentration, are both first-order reactions and possess rates of similar magnitude, due to kinetics of these two reactions for lignocellulosic materials. Moreover, hydrolysis time longer than optimum, enhances the speed of the second reaction and leads to a decrease in total sugar liberation. According to Talebnia et al., ${ }^{31}$ who studied the optimization of citrus waste saccharification by dilute-acid hydrolysis, the effect of time was not significant on RSY, while it represented a significant effect on the formation of HMF. This makes the variable 'time' one of the important factors for the hydrolysis.

According to HPLC results of the current study, none of the hydrolysates contained furfural or HMF. This is a great advantage for a fermentation media, since these compounds show inhibitory effects on microorganisms. This result could be partly related to phosphoric acid which is a much milder acid than $\mathrm{H}_{2} \mathrm{SO}_{4}$ bringing the advantage of using higher concentrations attacking larger surface areas and leading to higher decomposition of lignocellulosic material. Furthermore pectin was not hydrolysed in this study, and therefore no galacturonic acid peaks were detected through the HPLC analysis (data not shown). Due to inductive and conformational effects, the glucosidic bonds between galacturonic acid units were probably too resistant to phosphoric acid hydrolysis. ${ }^{31}$ Moreover the lack of furfural and HMF could also be explained by the low concentration of arabinose in the hydrolysates, 
since the reactivity of arabinose is the lowest among others sugars. ${ }^{34}$ Low percentages of $\mathrm{H}_{2} \mathrm{SO}_{4}$ (up to $0.5 \%$ ) showed sugar decomposition in many researches, dealing with the optimization of acid hydrolysis. ${ }^{27,31,35}$

\subsection{FTIR Analysis of Pomace Hydrolysates}

Using FTIR could be significantly advantageous to simultaneously predict the sugar profiles, soluble solid content and reducing sugars of various fruit pomaces. Therefore, hydrolysate samples of screening experiments were scanned using FTIR spectrometer. A sample FTIR spectra for apple pomace treated at various conditions are shown in Figure 3. Detailed assignments regarding FTIR absorption bands for apple juice is provided by Kelly and Downey. ${ }^{36}$ Same type of absorption bands were also observed for apple pomace samples. The peaks in the range of $1400-900 \mathrm{~cm}^{-1}$ are mostly associated with sugars and peak around $1725 \mathrm{~cm}^{-1}$ is attributed to $\mathrm{C}=\mathrm{O}$ bonds of organic acids. Partial least square (PLS) analysis was used to predict the concentration of several sugars, reducing sugar content and soluble solids ( $Y$ variables) in hydrolyasate samples using FTIR data as $X$ variables. Total number of samples for each fruit hydrolysates was 21. Since the number of samples were limited it was not possible to use a validation set; therefore, crossvalidation approach was preferred. Application of second derivative transformation to data improved the goodness of models except for apple samples. There was no need for data pretreatment for apple pomace samples. PLS models developed for apple pomace had $R_{\text {calib }}^{2}=0.99$ and $R T_{\text {cross-valid }}^{2}=0.99$. Other models developed had $R_{\text {calib }}^{2}$ values of $0.98,0.99$ and 0.98 and $R_{\text {cross-valid }}^{2}$ values of 0.58 , 0.68 and 0.45 for peach, apricot and orange pomaces, respectively. $R^{2}$ values for the prediction models were 0.99 (glucose), 0.98 (xylose), 1 (galactose), 0.99 (arabinose), 0.99 (fructose), 0.98 (brix) and 0.99 (reducing sugar). Slope of the prediction equations were very close to 1 .

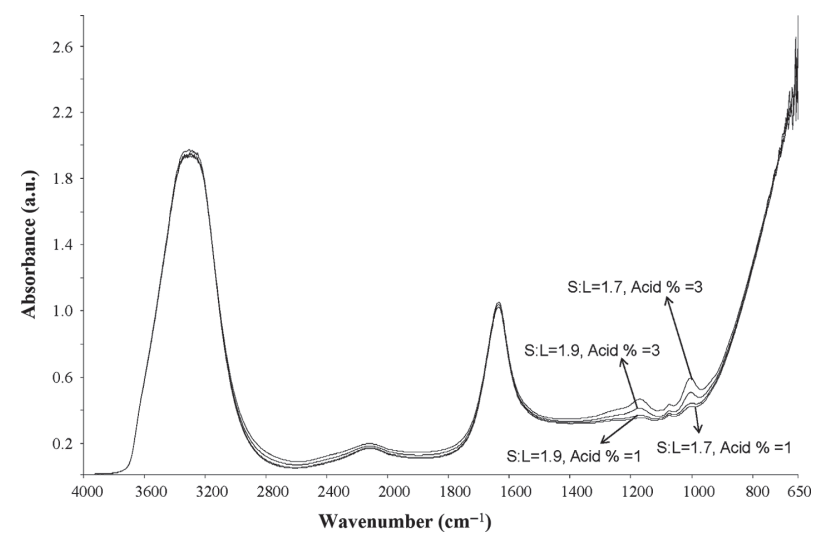

Fig. 3. FTIR spectra of apple pomace with various solid liquid ratio (S:L) treated at different acid concentrations at $126 \mathrm{C}$ for $20 \mathrm{~min}$. Notes: *replicate numbers were given in materials and methods section.
High $R^{2}$ values and slope values close to 1 mean good prediction value of the model. Statistical analysis results showed that FTIR has the potential of predicting the sugar profile, soluble solids and reducing sugar content of different fruit pomaces. However, developed models could be improved further by analyzing more samples for each fruit and also using more fruit varieties.

\subsection{Investigation of the Potential of Apple Pomace Hydrolysate in the Production of Bioethanol Using Trichoderma harzianum}

The direct fermentation of cellulosic biomass to ethanol has long been a desired goal, in order to lower the costs associated. Some filamentous fungi hold promise in this area, since they posses some advantages;

(i) they can be directly inoculated onto cellulosic biomass as they do not require strictly anaerobic conditions,

(ii) they facilitate separation of cell mass from the broth, due to their filamentous growth habit,

(iii) the inoculation in the forms of spores makes the inoculation of non-sterile biomass more practical. ${ }^{37}$

There are several reports about filamentous fungi such as Aspergillus, Rhizopus, ${ }^{23}$ Monilia ${ }^{38}$ Neurospora ${ }^{39}$ and Fusarium, ${ }^{40}$ that these fungi are capable of directly fermenting cellulose to ethanol.

In this study, for demonstration purpose the potential of apple pomace hydrolysate was investigated in the production of bioethanol using Trichoderma harzianum capable of fermenting microcrystalline cellulose or several sugars to bioethanol. This way, besides initial reducing sugars, remaining cellulosic compounds in hydrolysates could be fermented to bioethanol as well. Stevenson and Weimer ${ }^{37}$ found that, since Trichoderma harzianum could not actively grow under anaerobic conditions, bioethanol production was increased by a vented pre-growth cycle to enhance the initial amount of mycelia used in the fermentation. Therefore, in the current study, a pre-growth cycle was applied in order to increase the mass of mycelia and initiate fermentation using apple pomace hydrolysate as fermentation medium, obtained from pretreatment under predetermined optimum conditions. In order to observe the effect of some physical and chemical conditions, fermentations were carried out in different incubators; static, shaking (at $170 \mathrm{rpm}$ ) and $\mathrm{CO}_{2}$ incubators with cultures pre-grown in different media compositions such as rich YPM and minimal YNB.

Sugar profiles during the fermentation period, carried out in the $\mathrm{CO}_{2}$, static and shaking incubators were presented in Figures 4(a)-(c). It was reported by Stevenson and Weimer, ${ }^{37}$ that microorganism do not produce notable bioethanol during the first four days of fermentation. Based on this, measurements were started at fourth day of incubation in order to reduce the number of samplings. It was observed from the plots that the microorganism was using 
(a)

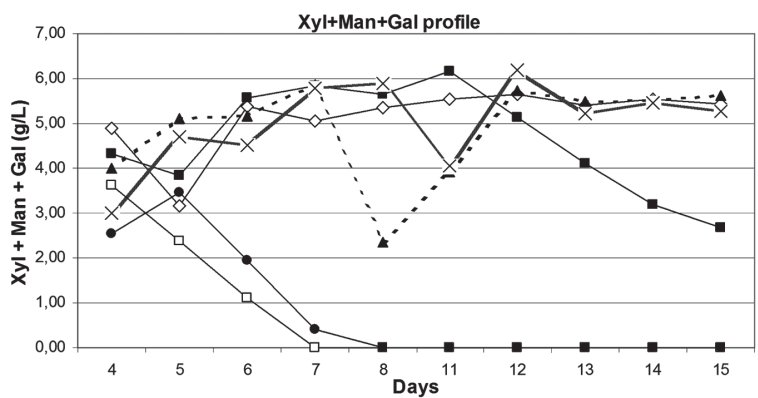

(b)

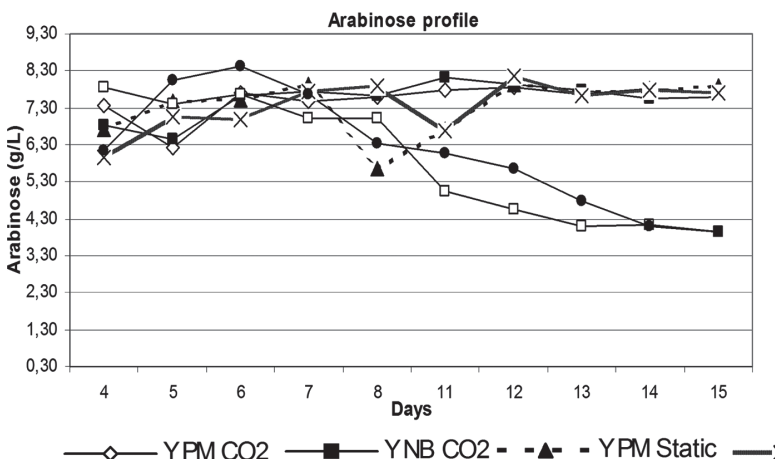

(c)

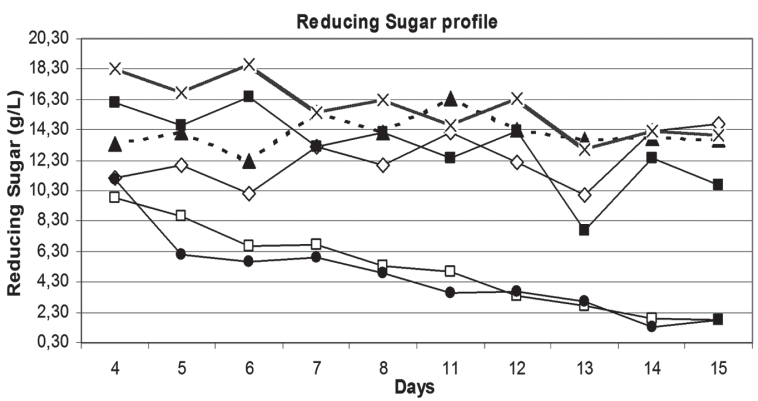

(d)

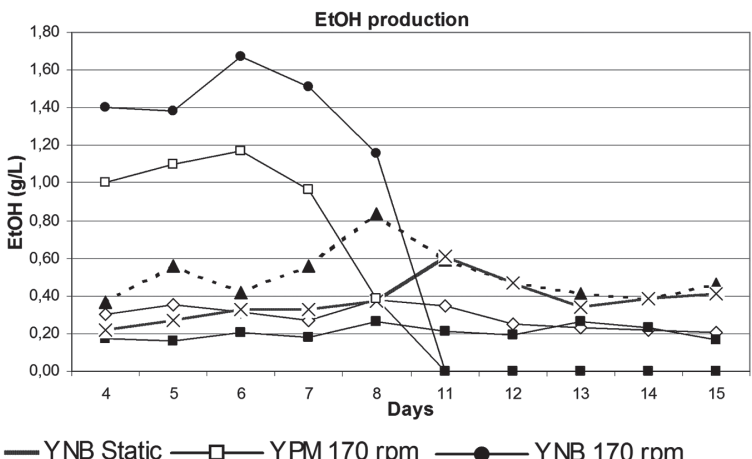

Fig. 4. Sugar profile (a)-(c) and bioethanol production (d) of apple hydrolysate fermentation using Trichodermaharzianum from different pre-grown media (YPM and YNB). (Replicate numbers were given in Mat and Met).

the sugars in the hydrolysates and breaking down the cellulose into sugars, simultaneously. Bioethanol production profiles of fermentations carried out in each incubator are discussed briefly below as depicted in Figure 4(d).

$\mathrm{CO}_{2}$ incubator: According to the bioethanol profiles, after eight days of fermentation there was a little reduction in the production. Apart from that, the average bioethanol production remained almost invariably and lowest for the rest of the duration. There were not any significant differences between YPM and YNB pre-grown cultures regarding both bioethanol production and sugar consumption. Using $\mathrm{CO}_{2}$ incubator caused adverse effect in bioethanol production in comparison to other incubators.

Static incubator: In the first eight days, YPM pre-grown cultures consumed sugars more effectively than YNB where this consumption reached its maximum at 8th day. That might be the reason why on the 8th day bioethanol production of YPM reached its maximum. However, the sugar consumption and bioethanol production of YPM and YNB were almost equal after 8th day, which continued to decrease. This was probably due to the over accumulation of mycelia, leading to inefficient mass transfer.

Shaking incubator: Since there was an efficient mass transfer of sugar compounds and a little $\mathrm{O}_{2}$ access through silicone tubing in shaking incubator at $170 \mathrm{rpm}$, microorganisms were able to use sugars and other compounds much more effectively in comparison with other incubators. This led to greater ethanol production in shaking incubator. In day six, the highest bioethanol production in both YPM and YNB (1.17 g/L, $1.67 \mathrm{~g} / \mathrm{L}$ respectively) cultures was achieved. However, YNB showed higher bioethanol production than YPM. The reason might be that there was higher biomass accumulation in rich medium than minimal medium, which reduced mass transfer on $\mathrm{O}_{2}$ access, indicating that over accumulation affected bioethanol production negatively. After six days bioethanol production in both media showed a fast decrease. Surely, the reason for this might be that microorganisms might have used all of the sugars because of the efficient mass transfer for biomass production and were not able to produce more bioethanol. Another reason could be the consumption of bioethanol by microorganisms as a carbon source.

There are very few studies available, where apple pomace has been used in bioethanol production. These are performed mainly in solid-state fermentation mode under various conditions. In fact these studies reported a maximum bioethanol yield ranging between $2.08-8.44 \% .^{41-44}$ Indeed, a direct comparison with our current study, which has been done in submerged fermentation with apple pomace hydrolysate, could not be made. In a more closer study to ours, conducted by Stevenson and Weimer, ${ }^{37}$ they achieved $5 \mathrm{~g} / \mathrm{L}$ bioethanol in 20 days using Trichoderma harzianum in a fermentation medium containing $50 \mathrm{~g} / \mathrm{L}$ glucose. Compared to this study, our current study has advantage of shorter fermentation time and using minimal pre-grown media and apple hydrolysate consisting of approximately $25 \mathrm{~g} / \mathrm{L}$ sugar. In another study conducted 
Table VI. Overall summary of studies performed using apple pomace and its hydrolysate.

\begin{tabular}{|c|c|c|c|}
\hline Organism & $\begin{array}{l}\text { Fermentation } \\
\text { type }\end{array}$ & $\begin{array}{c}\text { Max. } \\
\text { EtOH }(\%)\end{array}$ & Reference \\
\hline S. cerevisiae ATCC 24702 & Solid state & $2.08 \mathrm{w} / \mathrm{w}$ & [43] \\
\hline $\begin{array}{l}\text { S. cerevisiae Montrachet } \\
\text { strain } 522\end{array}$ & Solid state & $4 ., 0 \mathrm{w} / \mathrm{w}$ & [44] \\
\hline S. cerevisiae MTCC 173 & Solid state & $8.44 \mathrm{v} / \mathrm{w}$ & [41] \\
\hline S. cerevisiae & Solid state & $4.50 \mathrm{v} / \mathrm{w}$ & [42] \\
\hline \multirow[t]{4}{*}{ S. cerevisiae } & Submerged & & [45] \\
\hline & A.j. ${ }^{*}$ & $6.9 \mathrm{w} / \mathrm{v}$ & \\
\hline & A.p.e.** & $4.3 \mathrm{w} / \mathrm{v}$ & \\
\hline & A.p.e. with sucrose & $7.3 \mathrm{w} / \mathrm{v}$ & \\
\hline $\begin{array}{l}\text { Trichoderma harzianum } \\
\text { strain A10 }\end{array}$ & Submerged & $0.5 \mathrm{w} / \mathrm{v}$ & [37] \\
\hline $\begin{array}{l}\text { Trichoderma harzianum } \\
\text { strain A10 }\end{array}$ & Submerged & $0.16 \mathrm{w} / \mathrm{v}$ & $\begin{array}{r}\text { Current } \\
\text { study }\end{array}$ \\
\hline
\end{tabular}

Notes: *Apple juice; **Apple pomace extract.

by Nogueira et al. ${ }^{45}$ who evaluated the alcoholic fermentation of the apple juice, apple pomace extract and pomace extract added with sucrose using Saccharomyces cerevisiae, they achieved $6.9 \%, 4.3 \%$ and $7.3 \%$ bioethanol, respectively. This study indicated that $S$. cerevisiae shows high bioethanol production in sugar rich media. However, using a mixture of $T$. harzianum and $S$. cerevisiae in a media, which contains less sugar and more cellulose like in our current study may greatly impact bioethanol production, due to the ability of Trichoderma degrading cellulose. An overall summary presenting these studies is tabulated in Table VI.

Although the current amount of bioethanol (1.6 g/L) obtained seems to be low, it can be further improved by taking into account other important process parameters in order to utilize the apple pomace more, effectively. These could be for example the $\mathrm{pH}$ of the medium, the strain type (with the possibility using genetic manipulations), using certain bioreactor designs, aeration and nutrient supplementation and solid state fermentation mode.

Overall this study demonstrated that apple pomace hydrolysate could be potential candidate for bioethanol production applying fungal organisms. It also indicated that other pomace hydrolysates could exhibit similar attributes. In fact this study opens up a new window for the utilization of agro-industrial wastes for value-added products. Furthermore, the environmental pollution due to these wastes is prevented and a return with economical gain and benefit to the society is obtained. In fact this study is just preliminary and needs to be optimized further with respect to fermentation parameters and possibly combining various fruit pomaces for maximum bioethanol production.

\section{CONCLUSION}

Fruit pomaces, with identified chemical composition, were hydrolyzed with dilute acid and their optimum conditions and influencing factors were investigated utilizing two step statistical experimental design. Sugar yields of all pomaces at the end of optimization were higher $(31 \%$ for apple, $49 \%$ for apricot, $56 \%$ for orange and $52 \%$ for peach pomace) and none of hydrolysates contained either furfural or HMF. Although the highest bioethanol production from apple pomace hydrolysate, using Tricoderma harzianum was initially only $1.67 \mathrm{~g} / \mathrm{L}$ on the 6 th day in a shaking incubator, this is only a preliminary study, which holds a potential to be increased with further optimization study of the fermentation parameters. In fact, this study evaluated the use of selected fruit pomaces as agroindustrial waste by providing end user the determined optimum dilute acid hydrolysis pretreatment conditions and demonstrated their potential usage in bioethanol production as a key for the production of possible many other value-added products via microbial fermentations, which may utilize these effectively.

Acknowledgment: Support of KONFRUT Fruit Juice Concentrates and Purees Inc. in providing the fruit pomaces and of Izmir Institute of Technology, Biotechnology and Bioengineering Research and Application Center are greatly acknowledged.

\section{References}

1. F. Demirbas, K. Bozbas, and M. Balat, Energy Explore Exploit 22, 355 (2004).

2. S. E. Jacobsen and C. E. Wyman, Applied Biochem. Biotech. 84,81 (2000).

3. A. Sheoran, B. S. Yadav, P. Nigam, and D. Singh, J. Basic Microb. 38, 123 (1998).

4. F. O. Licht, World Ethanol and Biofuels Report 6, 61 (2007).

5. C. Pilgrim, Status of the worldwide fuel alcohol industry, The Alcohol Textbook, 5th edn., edited by W. M. Ingledew, D. R. Kelsall, G. D. Austin, and C. Kluhspies, Nottingham University Press, Nottingham (2009), pp. 7-17.

6. RFA-Renewable Fuel Association, Annual world ethanol production by country. http://www.ethanolrfa.org/pages/statistics/ [accessed 10 February] (2011).

7. Renewable Fuel Association (6 March 2012) 'Accelerating Industry Innovation 2012 Ethanol Industry Outlook' (http//ethanolrfa3cdn. net/d4ad995ffb7ae8fbfe_1vm62ypzd.pdf). Renewable Fuel Association. http//ethanolrfa3cdn.net/d4ad995ffb7ae8fbfe_1vm62ypzd.pdf. Retriewed 18 March (2012). See pp 3,8,10,22 and 23

8. G. M. Walker, Bioethanol: Science and Technology of Fuel Alcohol, Graeme M. Walker and Ventus Publishing ApS (2010), pp. 8-34.

9. L. Dawson and R. Boopathy, BioResources 3, 452 (2008).

10. AIJN, European Fruit Juice Association: Market ReportLiquid Fruit 2010. http://www.aijn.org/pages/main/file.handler?f= AIJNMarketReport. 2010 pdf [accessed 10 February] (2011).

11. B. Min, J. Lim, S. Ko, K. G. Lee, S. H. Lee, and S. Lee, Bioresour. Technol. 102, 3855 (2011).

12. R. Arumugam and M. Manikandan, Asian J. Exp. Biol. Sci. 2, 246 (2011).

13. W. Zhou, W. Widmer, and K. Grohmann, Proc. Fla. State. Hort. Soc. 120, 310 (2007).

14. R. Wooley, M. Ruth, J. Sheehan, K. Ibsen, H. Majdeski, and A. Galvez, Lignocellulosic biomass to ethanol process design and economics utilizing co-current dilute acid prehydrolysis and enzymatic hydrolysis current and futuristic scenarios. Nat. Renewable Energy Lab. Tech. Rpt. Golden, CO, NREL (1999). 
15. A. McAloon, F. Taylor, W. Yee, K. Ibsen, and R. Wooley, Determining the cost of producing ethanol from corn starch and lignocellulosic feed stocks. Nat. Renewable Energy Lab. Tech. Rpt. Golden, CO, NREL (2000).

16. A. Aden, M. Ruth, K. Ibsen, J. jechura, K. Neeves, J. Sheehan, B. Wallace, L. Montague, A. Slayton, and J. Lukas. Lignocellulosic biomass to ethanol process design and economics utilizing cocurrent dilute acid prehydrolysis and enzymatic hydrolysis for corn stover scenarios. Nat. Renewable Energy Lab Tech Rpt. Golden, CO, NREL (2002).

17. M. C. Edwards and J. D. Peterson, Appl. Microbiol. Biotechnol. 95, 565 (2012).

18. W. Zhou, W. Widmer, K. Grohmann, Proc. Fla. State. Hort. Soc. 120, 310 (2007).

19. S. H. Krishna and G. V. Chowdary, J. Agricul. Food Chem. 48, 1971 (2000).

20. C. Martin, H. B. Klinke, and A. B. Thomsen, Enzyme Microb. Technol. 40, 426 (2007).

21. Association of Official Analytical Chemists-AOAC, Fruits and fruit products. in Official Methods of Analysis, 14th edition, Washington DC, USA. (1984).

22. M. Somogyi, J. Biol. Chem. 200 (1952).

23. C. D. Skory, S. N. Freer, R. J. Bothast, Biotechnol. Lett. 19, 203 (1997).

24. L. J. Wickerham and K. A. Burton, J. Bacteriol. 54, 363 (1948).

25. C. Paganini, A. Nogueira, N. C. Silva, and G. Wosiacki, Cî̀encia Agrot'ecnica Lavras 29, 1231 (2005).

26. A. F. Azhar, M. K. Bery, A. R. Colcord, R. S. Roberts, and G. V. Corbitt, Biotechnol. Bioeng. Symp. 11, 293 (1981).

27. M. J. Taherzadeh and K. Karimi, Int. J. Mol. Sci. 9, 1621 (2008).
28. J. Song, J. Huang, K. Xu, and Q. Zhao, Chinese J. Process Eng. 3, 5 (2003).

29. Y. P. Ma, H. L. Ma, C. Y. Chen, and H. Q. Du, Journal of Northwest Sci-Tech University of Agriculture and Forestry 11 (2004).

30. K. Grohmann, R. G. Cameron, and B. S. Buslig, Appl. Biochem. Biotechnol. 51, 423 (1995).

31. F. Talebnia, M. Pourbafrani, M. Lundin, and M. J. Taherzadeh, Bioresour. Technol. 3, 180 (2008).

32. R. Fogel, R. Garcia, R. Olivera, D. Palacio, L. Madeira, and N. Pereira, Applied Biochem. Biotech. 122, 741 (2005).

33. J. F. Saeman, Ind. Eng. Chem. Res. 37, 43 (1945).

34. E. R. Garrett and B. H. Dvorchik, J. Pharmaceutical Sci. 58, 813 (1969).

35. H. S. Oberoi, P. V. Vadlani, K. Brijwani, V. K. Bhargav, and R. Pati, Process Biochem. 45, 1299 (2010).

36. J. F. D. Kelly and G. Downey, J. Agric. Food Chem. 53, 3281 (2005).

37. D. M. Stevenson and P. J. Weimer, Appl. Microbial. Biotechnol. 59, 721 (2002).

38. C. Gong, C. M. Maun, and G. T. Tsao, Biotechnol. Lett. 3, 77 (1981).

39. V. Deshpande, S. Keskar, C. Mishra, and M. Rao, Enzymol. Microb. Technol. 8, 149 (1986).

40. A. Singh and P. K. R. Kumar, Crit. Rev. Biotechnol. 11, 129 (1991).

41. D. K. Chantanta, K. Gopal, M. Devi, G. Gupta, T. C. Bhalla, and C. Attri, Internet J. Microbiol. 5, 2 (2008).

42. V. K. Joshi and D. K. Sandhu, Bioresour. technol. 56, 251 (1996).

43. M. O. Ngadi and L. R. Cooeria, J. Food Eng. 17, 97 (1992).

44. Y. D. Hang, C. Y. Lee, E. E. Woodams, and H. J. Cooley, Appl. Environ. Microbiol. 42, 1128 (1981).

45. A. Nogueira, L. D. Santos, C. Paganini, and G. Wosiacki. Semina Ci^encias Agr'arias Londrina 26, 179 (2005).

Received: xx Xxxx xxxx. Accepted: Xx Xxxx xxxx. 